\title{
Antibiotic Resistance Creating New Epoch
}

Praveenya $\mathrm{P}^{1 *}$, Brijesh Kumar Singh ${ }^{2}$, Sathish Kumar $\mathrm{D}^{3}$ and Purvi Kalyan ${ }^{1}$

${ }^{1}$ Institute of Science and Technology, Centre for Biotechnology, JNTUH, Hyderabad, India

${ }^{2}$ Department of Biotechnology, Satyabhama University, Chennai, Tamilnadu, India

${ }^{3}$ Department of Biotechnology, University of Hyderabad, Hyderabad, India

\begin{abstract}
Antibiotics are an efficient means of treating bacterial infections. They help in the reduction of mortality and morbidity. Discovery of antibiotic has created a new epoch where infectious diseases have been put to an end. But the organisms have developed resistance during the course of evolution due to mutations. The major problem which is being faced is the treating of infectious diseases caused by microbes which have developed resistance. The antibiotic resistance is being carried by the organisms due to acquisition of resistance genes to next generations by horizontal gene transfer. The present review is focused on what are the various mechanisms adopted by the organisms against antibiotics and new techniques involved in treating the infectious diseases and methods to overcome the antibiotic resistance.
\end{abstract}

Keywords: Antibiotic resistance; Multi Drug Resistance [MDR]; Methicillin Resistance Staphylococcus aureus [MRSA]; XDR-TB

\section{Introduction}

Antibiotics are the chemical substances that are antagonistic to the growth of microorganisms which are ubiquitous in nature. They are either produced by microorganisms or prepared synthetically. Penicillin was the first antibiotic discovered by Alexander Flemming from the fungi named Penicillium [1]. All penicillins are $\beta$-lactam antibiotics (Figure 1) used to treat bacterial infections in clinical medicine. Cephalosporins \& Carbapenems are also included in $\beta$-lactam antibiotics. They are classified into two groups based on their biological activity on microorganisms Bactericidal which kills the microbes, Bacteriostatic (erythromycin) [2] which inhibits the growth of microorganisms.

Antibiotics are classified based on spectrum.

- Wide / Broad spectrum

- Narrow spectrum

Broad spectrum antibiotics effects several types of bacteria and fungi, they acts both on Gram-negative and Gram-positive Bacteria, where as Narrow spectrum antibiotics are specific towards some bacterial families. Penicillins fall under broad spectrum of antibiotics which are effective against a wide range of bacteria. And hence the consistent use of such antibiotics has led to the emergence of resistance of antibiotics in microbes creating new epoch.

Antibiotics include Antibacterials, Antifungals, Antimalarials, Antivirals.

\section{Antibacterials}

The compounds that act against the bacteria are called antibacterials. Antibacterials can kill or inhibit the growth of bacteria. Antibacterials are the most important medications used in health care [3]. They play a pivotal role in combating many bacterial infections. Most of the Antibacterials are semisynthetic natural compounds like penicillins, carbapenems, cephalosporins. Whereas sulfonamides, Quinolones and oxazolidinones are purely synthetic compounds. Ofloxacin [OFX] is antimicrobial agent with a broad antimicrobial spectrum against Gram-positive and Gram-negative bacteria and is considered safe. It interferes with the enzyme DNA gyrase which is essential for synthesis of DNA [4]. Silver nanoparticles are emerging trends in nanosciences technology which are used as antibacterials to fight infectious organisms [5]. The Potential pathogenic bacteria are administered into the

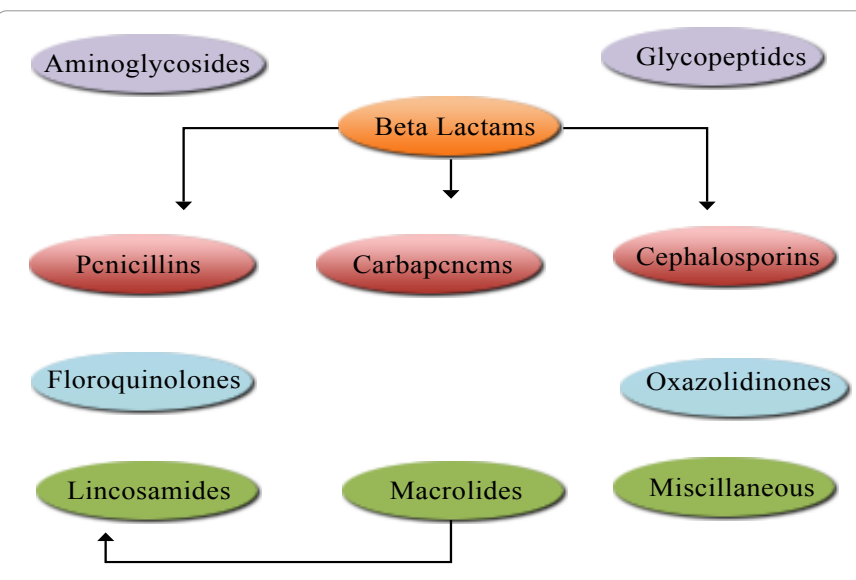

Figure 1: Classification of Antibiotics.

body by ingestion or through eyes when rubed with contaminated fingers [6]. And this type of administration of pathogens can be restricted by using disinfectants.

\section{Antifungals}

The compounds which are antagonistic to the growth of fungi are called Antifungals. Fungal organisms can cause great harm and damage. They infect people, animals and plants, producing diseases that range in seriousness from mild infection to death [7]. Mycosis is a fungal infection caused in animals and humans. Inhalation of fungal spores or localized colonization of the skin may initiate persistent infections, therefore mycoses often start in the lungs or on the skin. Invasive mycoses associated with high morbidity and mortality rates are increasing among immunocompromised or severely ill patients [8].

*Corresponding author: Praveenya $\mathrm{P}$, Institute of Science and Technology, Centre for Biotechnology, JNTUH, India, E-mail: praveenyapasumarthy@gmail.com

Received December 05, 2011; Accepted February 04, 2012; Published February 20, 2012

Citation: Praveenya P, Singh BK, Sathish Kumar D, Kalyan P (2012) Antibiotic Resistance Creating New Epoch. J Bacteriol Parasitol 3:131 doi:10.4172/21559597.1000131

Copyright: (c) 2012 Praveenya P, et al. This is an open-access article distributed under the terms of the Creative Commons Attribution License, which permits unrestricted use, distribution, and reproduction in any medium, provided the original author and source are credited. 
Various types of antifungals are in use to treat fungal infections and diseases.

Polyene antifungals: A molecule with multiple conjugated double bonds is called polyene. This interacts with sterols of cell membrane of fungi which makes channels in the membrane ejecting the monovalent ions and small organic molecules out of the cell leading to the death of the cell.

Azole antifungal drugs: Fluconazole, itraconazole, and ketoconazole inhibit cytochrome $\mathrm{P}_{450}$-dependent enzymes (particularly C-14demethylase) involved in the biosynthesis of ergosterol, which is essential for fungal cell membrane structure and function. Voriconazole is a fluconazole with enhanced antifungal spectrum. It is like other azole antifungals, alters the cell membrane function and permeability, resulting in cell dysfunction [9]. Voriconazole is a safe promising and cost effective antifungal [10].

\section{Anti malarials}

Compounds which act against malaria causing Plasmodium falciparum are called antimalarials [11]. Malaria is caused by a parasite from plasmodium species that is passed from one human to another by the bite of infected Anopheles mosquitoes. Malaria involves high fevers, shaking chills, flu-like symptoms, and anemia. The parasites after infection are called sporozoites travel through blood stream to liver and mature over there and release merozoites. The parasites multiply in the red blood cells.

The major symptoms observed in malaria are:

- Merozoites are released into blood stream

- Hemoglobin is released into circulation on breakage of redblood cells

- Anemia as a result of destruction of redblood cells

Hydroxychloroquine \& chloroquine are anti-malarial medications used effectively active against malaria. Quinine is an alkaloid which acts as a blood schizonticidal. Quinine is less effective and more toxic as a blood schizonticidal agent than chloroquine.

Due to the acquired global resistance of malaria parasites to antimalarial drugs, there is need for new approaches to malaria treatments. Targeting of enzymes which play pivotal roles in the parasite's life cycle is being executed to overcome the resistance of the organism [12] Treatment with cysteine protease inhibitors blocks hemoglobin hydrolysis and parasite development in vitro.

\section{Antivirals}

The compounds which are antagonistic to the viral particles are called antivirals. Viruses are constantly plaguing the world, causing severe infections and mortality [13]. Dengue virus is transmitted to humans through bites of mosquito species, Aedes aegypti and A. albopictus [14]. The emergence of antiviral drugs is the expanded knowledge of the genetic and molecular function of organisms by biomedical researchers. Sulfated polysaccharides (sPS), in particular dextran sulfate (DS) and related polyanionic compounds have been shown to be active against various viruses [15].

\section{Mechanism of action of Antiviral:}

- In Influenza A virus uncoating is inhibited by amantadin and rimantadin

- Gamma globulins neutralize the viral particles.
- Viral DNA polymerase is inhibited by guanosine derivative Acyclovir in Herpes virus.

- Gancyclovir is a guanosine derivative which is phosphorylated and incorporated into viral DNA inorder to suppress its replication in cytomegalovirus.

- Neuramidase is an enzyme essential for virus replication; this is inhibited by the drugs Zanamivir and Oseltamivir in H1N1 \& H5N1 cases.

- Interferon's and Monoclonal antibodies are found active against viral infections.

HAART is an antiretroviral therapy in use nowadays. It consists of combination of 3 antiviral drugs with one protease inhibitor [16]. Since this therapy is in use the decrease in mortality and morbidity is observed [17].

\section{Disadvantages of antibiotics}

- They cause allergic response inducing hyper sensitivity.

- The possible side effects are observed in the treatment of diseases, although these should be rare at the doses and length of time of treatment [18].

- Antibiotics destroy friendly bacteria present in the body that helps in detoxification, elimination of waste and cleansing of the blood and Liver.

- The persistent use of antibiotic to the bacteria causes bacteria accustomed with it and no longer get effected by antibiotics, transforming into drug resistant bacteria.

- The bacterium acquires the resistance gene and transfers them to next generations, multiplying the drug resistance bacteria.

- Antagonism between antibiotics contributes to the disadvantages of the inappropriate use of antimicrobial combinations [19].

\section{Antibiotic Resistance}

Antimicrobial resistance is the resistance of microorganisms to antimicrobials like antibiotics and drugs. Infectious diseases caused by microorganisms which are resistant to antimicrobials often results in prolonged illness and greater risk of death. Antibiotic resistance bacteria have posed severs threat to public health [20].

Organisms that display multidrug resistance are

- Pathologic cells.

- Neoplastic cells.

\section{Pathologic cells include bacterial cells}

MDR \& XDR-TB are the two deadly forms of TB which are resistant to the drugs used in treating TB and imposing threat to human beings [21,22]. Streptococcus pneumonia is an important pathogen causing a variety of diseases including pneumonia, meningitis, and otitis [23]. Staphylococcus aureus is a major cause of various hospital acquired infections. These infections range from superficial skin infections to deeper infections of hair follicles, abscesses, and deep tissue infections and even to systemic infections including those of the heart, lungs, bones, and blood [24]. Staphylococcus aureus is an important pathogenic facultative Gram-positive bacterium [25] which has acquired resistance; it also forms biofilms which are the bacterial community that encloses themselves in a polymer matrix [26]. The adeB gene found in MDR strains confers resistance to aminoglycosides and tetracyclines in Acinetobacter baumannii [27]. Pseudomonas aeruginosa is an emerging opportunistic and nosocomial pathogen infecting only compromised 
tissues and causing pathology in the gastrointestinal tract [28]. Drug resistant mycobacterium is increasingly common in different parts of the world and is fueled with spread of Acquired Immunodeficiency Syndrome (AIDS) [29].

Eg; Methicillin Resistant Staphylococcus aureus (MRSA), Pseudomonas aerginosa, Acinetobacter baumannii, Mycobacterium tuberculosis.

\section{Neoplastic cells include tumor cells}

Multidrug resistance, the principal mechanism by which many cancers develop resistance to chemotherapy drugs, is a major factor in the failure of many forms of chemotherapy. It affects patients with a variety of blood cancers and solid tumors, including breast, ovarian, lung, and lower gastrointestinal tract cancers. Tumors usually consist of mixed populations of malignant cells, some of which are drug-sensitive while others are drug-resistant. Chemotherapy kills drug-sensitive cells, but leaves behind a higher proportion of drug-resistant cells. As the tumor begins to grow again, chemotherapy may fail because the remaining tumor cells are now resistant.

\section{Causes of antibiotic resistance}

- Antibiotic abuse

\section{- Horizontal Gene Transfer}

Antibiotic abuse: Drug abuse has become increasingly common these days [30]. Inappropriate use of prescriptions for antibiotics creates new, drug-resistant strains of common diseases. Prescribing antibiotics carefully and using them wisely is the key to preventing the spread of antibiotic-resistant illnesses. The premature breaking of the antibiotic doses by patients is also a major cause of antibiotic abuse.

The Antibiotics were given along with the feed to the live stock in order to reduce the infections and increase the rapid growth of the animals. This ultimately increases the risk of germs which pass onto humans making them resistant to antibiotics. Implementation of reduced prescription of antibiotics showed a remarkable decrease in drug resistant strains [31].

Horizontal aene transfer: A spontaneous genetic mutation confers resistance to the drugs in bacteria. Generally more than one mutation is required to provoke drug resistance. Many of the antibiotic resistant genes reside on plasmids which are passed onto next generations through horizontal gene transfer (Figure 2). The resistant genes are conceded to the next generations by transformation, transduction or conjugation, thus multiplying the population of resistant bacteria.

Drug resistance in Neoplastic cells: Chemotherapy is used to treat cancer. Some of the cancer cells which were not killed by chemotherapy mutate and the mutated cells proliferate passing on the drug resistance to the newly formed cells. Apoptosis and Senescence are the two main programs which help the drugs in treating cancer. Mutations which alter these programmes will lead to chemoresistance in tumor cells.

Cancer is the continuous proliferation of the cells in the body. The lumps or masses produced due to uncontrolled growth are called tumors [32]. Cancer is of two types Benign and Malignant. Uncontrolled invasive growth is main characteristic of malignancy, and metastasis is in most cases the reason why cancer patients die [33].

Tumor cells contain oncogene that has ability to cause cancer. Apoptosis is the programmed cell death practiced by many normal cells. Resistance to apoptosis leads to the progression of solid cancers [34]. Numbers of factors are responsible for cancer genesis. Loss of control of

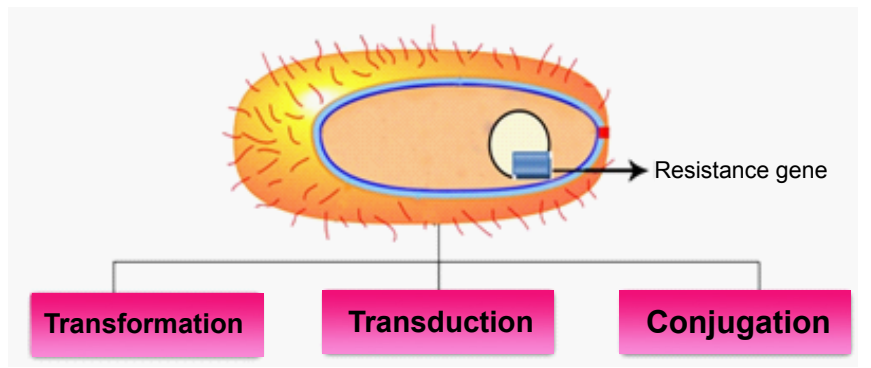

Figure 2: Horizontal Gene Transfer.

cell cycle, Angiogenesis, Cellular neoplastic transformation, Resistance to apoptosis, and acquisition of invasive properties initiate the growth of solid tumors [35]. Chemotherapy is used to treat cancer. Chemotherapy means use of chemical compounds in the treatment. The persistent use of chemical compounds has resulted in resistance of cancer cells. Resistance could also result from alterations in cell proliferation [36].

The major Hindrance in cancer treatment is acquired resistance to chemotherapy, there are several methods employed by cancer cells to resist the treatment.

- Cells which are not killed by chemotherapy mutate and develop drug resistance.

- Over production of proteins by gene amplification renders anticancer drug ineffective

- Cancer cells drive out the drug before it reaches the targeted site

- Transport channels across the membrane stop working and inhibits the drug uptake

- Patients with circulating tumor cells expressed MRP1 and MRP2, two drug-export pumps responsible for anthracyclines efflux[37].

Various other means of treatment are being investigated to fight cancer. Many new techniques has evolved to treat cancer. Neoadjuvant Chemotherapy is in practice to treat breast cancer [38]. Neoadjuvant chemotherapy is done prior to surgery making the cancerous cells shrink in size giving a clear distinction between cancer cells and healthy tissue surrounding it inorder to decrease the damage caused to healthy tissue during surgery [39].

Bacterial cells interact with tumor cell lines in brain tumor which advances the treatment of brain tumor with bacterial cells [40]. $\gamma$-Tocotrienol is one of the eight natural isoforms that make up the family of vitamin $\mathrm{E}$ compounds and displays potent antiproliferative and apoptotic activity against neoplastic mammary epithelial cells [41]. Coordination compounds have found to be effective as antineoplastic compounds[42]. Agaricus sylvaticus assess the antioxidant potential which helps in preventing pre mature aging and cancer [43]. Angioinhibitors are also available naturally. Consumption of natural angioinhibitors can help prevent cancer [44]. miRNAs can delineate cervical cancer from normal cervical tissue, and miRNAs have potential as markers for progression from dysplasia to invasive cervical disease. EGF, PDGF as well as their receptors are implicated in experimental and human malignant diseases. Wounds and developing tumors are biologically similar niches of dynamic interaction between varieties of cell types sharing many histological features. For tissue repair and tumorigenesis, cell proliferation, migration, survival, and angiogenesis are 
instrumental events whereas all these processed appeared governed by a plethora of growth factors.

\section{Acquisition of resistance}

Microbes play different strategies to develop resistance some of them include.

Enzymatic Inactivation: $\beta$-lactam is a four memberd ring. It is a part of core structure of many broad spectrum antibiotics. The enzyme $\beta$-lactamases [45] hydrolyses the $\beta$-lactam ring disturbing the molecular structure of the antibiotics. Carbapenems are the antibiotics which are very efficient against the Gram-negative resistant bacteria.They are inhibited by the enzymes carbapenemases.Carbapenemases are the enzymes which confer resistant to carbapenems in Gram-negative Bacteria such as Pseudomonas aeruginosa. MBL are the metallo-betalactamases (IMP, VIM, SPM, GIM types) and are clinically significant carbapenemases. Carbapenamases are also active against amnoglycosides and quinolones. MBLs contain $\mathrm{Zn}^{+2}$ cation. They belong to the molecular class B family. They mediate resistance to beta lactams by cleaving the amide bond in beta lactam ring.

Drug impermeabilty: Organisms with high permability can develop resistance by decreasing the permeability. In Pseudomonas aeriginosa resistance is achieved by lacking the channel OprD which allows $\beta$-lactamase to pass through it. The hospital isolates of Pseudomonas aeruginosa has developed resistance by using this mechanism. The permeability depends on physicochemical properties of the outer membrane of the bacteria. Hydrophobic antibiotics are effective against Gram-positive bacteria rather than Gram-negative Bacteria. The lippopolysacharide layer contains less fluidity and confers rigidity to the outer membrane which doesn't allow the hydrophobic antibiotics penetrate through it. In Gram-negative bacteria diffusion of Hydrophilic antibiotics is accomplished by diffusion channels formed with the help of porin proteins. Nutrients, Products of metabolism,and cephalosporins drugs are diffused through porin channels. Lack of these porins ie; OmpF and OmpC [46] confers resistance to cephalosporins.

Efflux pumps: Active efflux is a mechanism responsible for extrusion of toxic substances and antibiotics outside the cell, this plays a pivotal role in xenobiotic metabolism. This mechanism contributes to bacterial antibiotic resistance. Efflux systems function via an energy-dependent mechanism (Active transport) to pump out unwanted toxic substances through specific efflux pumps. Tetracycline efflux is achieved by an export protein from the major facilitator super family (MFS) [47]. The export protein was shown to function as an electroneutral antiport system which catalyzes the exchange of tetracycline-divalent-metal-cation complex for a proton. The distinct energy dependent transpoters called efflux pumps extrude the antibiotics from the periplasm to the exterior of the cell. This efflux pump overproduction is generally accompanied by an increase in resistance to two or more structurally unrelated antibiotics and contributes to the emergence of multidrug pathogens.

Biofilms: Biofilms are the important survival mechanisms of bacteria. Biofilms protect bacteria against antibiotics and phagocytosis [48]. The microbes adhere to the surface and colonise. They can anchor more efficiently and permanently with the help of pili. They are mostly found on submerged areas and substrates in contact with aqueous solution. The RapA protein belongs to the SWi/SNF superfamily of helicase-like proteins, which has been implicated in chromatin remodeling in eukaryotic cells. In the RapA-deficient mutant, several genes were regulated, including the yhcQ and yeeZ genes. The yhcQ is putatively concerned with encoding a multidrug resistance pump and yee $Z$ with an unknown envelope function. The enhanced penicillin resistance of the wild type biofilm is due to a dual strategy: impaired penetration of the biofilm through its matrix, and rapid efflux of the antibiotic that still manages to penetrate. OprF is involved in adhesion to eukaryotic Cells and in biofilm formation under anaerobic conditions [49].

\section{How to overcome the problem?}

- Reducing the disease burden and the spread of infection

- Improving access to appropriate antimicrobials

- Improving use of antimicrobials

- Strengthening health systems and their surveillance capabilities

- Enforcing regulations and legislation encouraging the development of appropriate new drugs and vaccines.

- One area that has potential for development of new drugs is the formation of metal coordination complexes [50].

To combat antibiotic resistance is to strengthen the action of existing antibiotics by modifying them so the bacterial enzymes that cause resistance cannot attack them. Alternately, "decoy" molecules can be used along with the antibiotic, so that the bacterium's resistance enzyme attacks the decoy molecule rather than the antibiotic. Decoy molecules such as clavulanic acid or sulbactam are already in use for blocking the beta-lactamase enzymes that destroy the penicillin family of drugs.

An alternative approach to the antibiotic resistance problem is to interfere with the mechanisms that promote resistance, rather than to attempt to kill the bacteria. For example, interfering with the duplication or movement of a bacterium's genetic material would eliminate the transfer of resistance genes between bacteria.

\section{Re-engineered Drugs (Vancomycin)}

The new vancomycin analogue can grab hold of the mutant peptidoglycan, and again prevent the bacteria from making the cell wall and killing the resistant bacteria. the redesigned antibiotic maintains its ability to bind the wild type peptidoglycan as well. Changing the properties of a key amide at the core of the natural products structure required a new synthetic strategy that only the most talented chemists could achieve in the lab. The preparation of the entire structure took a great deal of time and a fresh approach.

\section{Apitherapy}

The Medical use of Honey and Honey Bee products like bee bread, bee venom, propolis, royal jelly, apilarnil is called Apitherapy. Honey has a potent antibacterial activity and is very effective in clearing wounds, infection by inhibiting a wide range of bacteria [51]. The invitro studies of honey revealed its anticancer and antifungal properties [52]. Melittin is the active component of bee venom which possess anti bacterial, antiinflamatory \& antiviral properties. Bee venom consists of peptides and proteins which have neurotoxic and immunogenic effects. Apitherapy has become the focus of interest as a form of alternative and preventive medicine for treatment of a number of clinical cases. Honey has been suggested as an effective healing agent in treatment of postoperative wounds. In many cases honey has cleaned up wounds when conventional treatment was unsuccessful. Commercial honey has been reported to accelerate wound healing when applied topically to experimentally induced wounds infection. Antibacterial activity of honey was attributed to hydrogen peroxide naturally present in it. The antiproliferative activity of Tualang honey was observed in treatment of Oral squamous cell carcinomas (OSCC) and Human Osteosarcoma (HOS). 
Surgery and Radiotherapy of OSCC \& HOS leads to reduced quality of life. Apoptotic cellular changes like becoming rounded, reduction in cell number, blebbed membrane and apoptotic nuclear changes like nuclear shrinkage, chromatin condensation and fragmented nucleus are observed in OSCC and HOS cell lines [53].

\section{Phage therapy}

Viruses carry only a minimal number of genes and thus, for replication they must pirate the cellular machinery of infected cells [54]. Bacteriophage is a virus that depends on bacterial cellular machinery for its survival [55]. The potential use of the phage for the control of both local and systemic human $S$. aureus infections has been observed in recent studies [56]. Bacteriophages are harmless not only to the host organism , but also to other beneficial bacteria, such as gut flora, reducing the chances of opportunistic infections. Bacterial phage therapy has proved extremely successful in the treatment of topical infections, as has the inhalation of phages for the treatment of lung infections. The ability of phages to prevent biofilm formation on medical devices has received much attention, mainly in the area of catheter coatings [57]. Phage therapy is considered to be safe compared to use of antibiotics. The bacteria release endotoxins when destroyed within the patients, this causes fever and toxic shock in extreme conditions. To overcome this situation genetically engineered bacteriophages are used which lacks endolysin producing gene, this keeps the destroyed bacteria intact because lysis stage is disabled. And the phages are phagocytosed by the phagocytes.

\section{Photodynamic therapy}

Light-activated antimicrobial agents (photosensitizers) are promising alternatives to antibiotics for the treatment of topical infections. To improve efficacy and avoid possible damage to host tissues, targeting of the photosensitizer to the infecting organism is desirable, and this has previously been achieved using antibodies and chemical modification of the agent. The study has investigated the possibility of using a bacteriophage to deliver the photosensitizer tin (IV) chlorin e6 (SnCe6) to Staphylococcus aureus. SnCe6 was covalently linked to S. aureus bacteriophage 75 , and the ability of the conjugate to kill various strains of S. aureus when exposed to red light was determined. Substantial kills of methicillin- and vancomycin-intermediate strains of $S$. aureus were achieved using low concentrations of the conjugate (containing $1.5 \mathrm{~g} / \mathrm{ml}$ SnCe6) and low light doses $\left(21 \mathrm{~J} / \mathrm{cm}^{2}\right)$. Under these conditions, the viability of human epithelial cells (in the absence of bacteria) was largely unaffected. On a molar equivalent basis, the conjugate was a more effective bactericide than the unconjugated SnCe6, and killing was not growth phase dependent. The conjugate was effective against vancomycin-intermediate strains of $S$. aureus even after growth in vancomycin. The results demonstrated that a bacteriophage can be used to deliver a photo sensitizer to a target organism, resulting in enhanced and selective killing of the organism. Such attributes are desirable in an agent to be used in the photodynamic therapy of infectious diseases.

\section{Active Plant Components for Therapeutic Use (Phyto Therapy)}

Use of higher plants to treat infections is an age-old practice in a large part of the world population [58]. Plant components are in use to treat infectious disease since ancient times. A plant contains many alkaloids produced as a result of metabolism. These secondary metabolites are very effective against disease causing microbes. Plants are rich in a wide variety of secondary metabolites, such as tannins, terpenoids, alkaloids, and flavonoids, which have been found in vitro to have antimicrobial properties. Flavonoids from Hypericum japonicum showed the liver protective ability. Quercetin (Q), quercetin-3-Orhamnoside (Q-3-R), quercetin-7-O-rhamnoside (Q-7-R) and quercetin-3-O-glucoside (Q-3-G) were administrated in mice to test its activity [59]. Flavonoids are natural occurring polyphenolic compounds that are widely distributed in the plant kingdom, displaying a wide range of pharmacologic properties, including anti-inflammatory, antioxidant, anticarcinogenic and anticancer activities [60]. Plants have provided a good source of anti-infective agents; emetine, quinine, and berberine remain highly effective instruments in the fight against microbial infections. Phytomedicines showed promising results in combating infectious diseases.

The alcoholic and aqueous extracts of plant parts are tested against the infectious microbes to estimate its activity. MIC [Minimum Inhibition Concentration], MBC [Minimum Bacterial Concentration], and Zone of Inhibition are the parameters used in evaluation of activity of plant components. The alcoholic and aqueous extracts of flower part of Cassia fistula showed antibacterial and antifungal activities. In Acacia aroma leaf and flower ethonolic extracts are effective against Gramnegative bacteria. Azhadiracta indica the neem plant is very well known for its antibacterial properties since ancient times. The administration of Methonolic extract of neem leaves inhibited hemorrhage induced by $V$. cholerae in mouse intestine unveiling its antihemorrhagic activity. Amadannulen is the novel compound present in Curcuma amada showed antibacterial property on both Gram-positive and Gram-negative bacteria. Phenolic extracts of maple showed antiproliferative properties by arresting the cell cycle in S phase [61]. The phytocompounds has been found active against biofilms formed of candida albicans [62].

The cytoplasmic extract of Kumazasa bamboo leaf exhibits potent bactericidal action against Gram-positive bacteria such as Staphylococcus aureus, MRSA, VRE [63]. Spices are being used for therapeutic purpose since ancient times. Many spices are in use as a household remedies for combating many infections [64]. Cinnamon, nutmeg, turmeric, black pepper etc. are used as anti inflammatory, antibacterial, antivirals and antioxidants. Natural products play a major role as starting material for drug discovery [65]. Drug discovery, it aims at identifying a compound therapeutically useful in treating and curing a disease.

\section{Conclusion}

The present review has focused on the different strategies employed by the microbes to resist the action of drugs on them. The various treatments in use to combat the antibiotic resistance. The current ongoing research to overcome this deadly resistance era is done by using plant materials and plant products. The alcoholic and aqueous extracts of plant parts are being used to resolve the resistance problem. Plant contains natural products and many secondary metabolites which are toxic and which can be used to treat deadly infectious diseases. The antibiotics are Re-engineered to combat the deadly resistant bacteria more effectively.

\section{Acknowledgement}

The authors would like to thank Sameera $V$ and Yashwanth kumar for their support and would like to express their gratitude to all those who made the work possible.

\section{References}

1. Bakshi DK, Dhanda V, Sagar V, Toor D, Kumar R, et al. (2010) Review and Analysis of Reported Anthrax-Related Military Mail Security Incidents in Washington D.C. Metropolitan Area During March 2005. J Bacteriol Parasitol 1: 103.

2. Zakeri-Milani P, Ghanbarzadeh S, Lotfi poor F, Milani M, Valizadeh H (2010) Pharmacokinetic Study of Two Macrolide Antibiotic Oral Suspensions Using an Optimized Bioassay Procedure. J Bioequiv Availab 2: 111-115. 
3. Reder-Christ K, Bendas G (2011) Biosensor Applications in the Field of Antibiotic Research-A Review of Recent Developments. Sensors 11: 9450-9466.

4. Shakya R, Hada M, Thapa P, Saha RN (2010) Comparative Bioavailability of Two Brands of Ofl oxacin in Healthy Human Volunteers. J Bioequiv Availab 2: $55-58$

5. An NT, Dong NT, Hanh PTB, Nhi TTY, Vu DA, et al. (2010) Silver-N-Carboxymethyl Chitosan Nanocomposites: Synthesis and its Antibacterial Activities. J Bioterr Biodef 1: 102

6. Daisy A, Kamaraj S (2011) The Impact and Treatment of Night Soil in Anaerobic Digester: A Review. J Microbial Biochem Technol 3: 43-50.

7. Essawy AE, Helal SF, El- Zoheiry AH, El- Bardan EM (2010) Hepatotoxicity Induced by Antifungal Drug Fluconazole in the Toads (Bufo Regularis). J Drug Metabol Toxicol 1: 106

8. Pemán J, Salavert M (2011) General Epidemology of invasive fungal disease Enferm Infecc Microbiol Clin 30: 90-98

9. Al-Badriyeh D, Leung L, Davies GE, Stewart K, Kong D (2009) Successful salvage treatment of Scedosporium apiospermum keratitis with topical voriconazole after failure of natamycin. Ann Pharmacother 43: 1139-1142.

10. Zufía L, Aldaz A, Ibáñez N, Giráldez J (2010) Validation of an LC Method for Therapeutic Drug Monitoring of Voriconazole in Patients. J Bioanal Biomed 2: $35-43$

11. Olliaro P, Ramanathan S, Vaillant M, Reuter SE, Evans, et al. (2010) Pharmacokinetics and Comparative Bioavailability of Artesunate and Mefl oquine Administered Separately or as a Fixed Combination Product to Healthy Volunteers and Patients with Uncomplicated Plasmodium falciparum Malaria. J Bioequiv Availab 2: 59-66.

12. Emmanuel A, Nok AJ, Mairo IH, Catherine AB, Emmanuel H, et al. (2011) Effect of Immunization with Cysteine Protease from Phase-Separated Parasiten Proteins on the Erythrocytic Stage Development of the Chloroquine-Resistant, Plasmodium berghei in BALB/C Mice. J Bacteriol Parasitol 2: 119.

13. Wee T, Jenssen H (2009) Influenza Drugs - Current Standards and Novel Alternatives. J Antivir Antiretrovir 1: 1-10.

14. Yin Low JS, Chen KC, Wu KX, Mah-Lee Ng M, Hann Chu JJ (2009) Antivira Activity of Emetine Dihydrochloride Against Dengue Virus Infection. J Antivir Antiretrovir 1: 62-71.

15. Radonić A, Thulke S, Achenbach J, Kurth A, Vreemann A, et al. (2010) Anionic Polysaccharides from Phototrophic Microorganisms Exhibit Antiviral Activities to Vaccinia Virus. J Antivir Antiretrovir 2: 51-55.

16. Gathe JC, Daquoiag B, Fuchs JE, Pakes GE (2010) Virologic and Immunologic Outcomes in Patients Switched from Amprenavir to Fosamprenavir in a Clinical Practice Setting. J AIDS Clinic Res 1: 109.

17. Sohaskey C (2011) Latent tuberculosis: is there a role for thioridazine? Recent Pat Antiinfect Drug Discov 6: 139-146.

18. Acar JF (2000) Antibiotic synergy and antagonism. Med Clin North Am 84 1391-1406.

19. El-Khatib Z, DeLong AK, Katzenstein D, Ekstrom AM, Ledwaba J, et al. (2011) Drug Resistance Patterns and Virus Re-Suppression among HIV-1 Subtype C Infected Patients Receiving Non-Nucleoside Reverse Transcriptase Inhibitors in South Africa. J AIDS Clinic Res 2: 117

20. Fjell CD, Hiss JA, Hancock RE, Schneider G (2011) Designing antimicrobia peptides: form follows function. Nat Rev Drug Discov [Epub ahead of print]

21. Singh R, Rajni, Meena A, Meena LS (2011) Multidrug resistant and Extensively drug resistant TB: A Nuisance to Medical Science. J Bacteriol Parasitol 2: 105.

22. Mittal R (2011) Mesenchymal Stem Cells: The New Players in the Pathogenesis of Tuberculosis. J Microbial Biochem Technol 3: e103.

23. Norcross EW, Sanders ME, Moore QC 3rd, Marquart ME (2011) Pathogenesis of A Clinical Ocular Strain of Streptococcus pneumoniae and the Interaction of Pneumolysin with Corneal Cells. J Bacteriol Parasitol 2: 108.

24. Gold HS, Pillai SK (2009) Antistaphylococcal agents Infect Dis Clin North Am 23: 99-131.

25. Elazhari M, Elhabchi D, Zerouali K, Dersi N, Elmalki A, et al. (2011) Prevalence and Distribution of Superantigen Toxin Genes in Clinical Community Isolates of Staphylococcus aureus. J Bacteriol Parasitol 2: 107.
26. Schillaci D (2011) Staphylococcal Biofilms: Challenges in the Discovery of Novel Anti-infective Agents. J Microbial Biochem Technol 3: e104

27. Ben Othman A, Burucoa C, Battikh H, Zribi M, Masmoudi A, et al. (2011) Com parison of Acinetobacter baumannii multidrugs resistant Isolates obtained from French and Tunisian hospitals. J Bacteriol Parasitol 2: 106.

28. Amin OM (2011) The Contribution of Pathogenic Bacteria to GI Symptoms in Parasite-Free Patients. J Bacteriol Parasitol 2: 109

29. Hu Y, Liang S, Zhu J, Qin G, Liu Q, et al. (2011) Factors Associated with Recen Risky Drug Use and Sexual Behaviors among Drug Users in Southwestern China. J AIDS Clinic Res 2: 120.

30. St-Onge R, Goyer C, Filion M (2010) Pseudomonas Spp. can Inhibit Strep tomyces scabies Growth and Repress the Expression of Genes Involved in Pathogenesis. J Bacteriol Parasitol 1: 101.

31. Shaper M (2011) Antibiotic Resistance in Streptococcus pneumonia: A Disaste in the making. Epidemiol 1: 102e.

32. Shimoyama S (2011) BRAF Mutations and their Implications in Molecular Targeting Therapies for Gastrointestinal Cancers. J Pharmacogenom Pharmacoproteomics 2: e102.

33. Skogseth H, Tvedt KE, Halgunset J (2011) Carcinoma Metastasis-An Ap proach to Models. J Carcinogene Mutagene 2: 119.

34. McBee WC Jr, Gardiner AS, Edwards RP, Lesnock JL, Bhargava R, et al. (2011) MicroRNA Analysis in Human Papillomavirus (HPV)-Associated Cervical Neoplasia and Cancer. J Carcinogene Mutagene 1: 114

35. Singh RK, Sudhakar A, Lokeshwar BL (2011) From Normal Cells to Malignancy: Distinct Role of Pro-inflammatory Factors and Cellular Redox Mechanisms. J Cancer Sci Ther 3: 70-75.

36. Surani JJ, Akbari VG, Purohit MK, Singh SP (2011) Pahbase, a Freely Available Functional Database of Polycyclic Aromatic Hydrocarbons (Pahs) Degrading Bacteria. J Bioremed Biodegrad 2: 116.

37. Li ZC, Li HJ, Dai LL, Gao YQ, Cai WP, et al. (2010) Liver injury in HIV-1-infected patients receiving non-nucleosides reverse transcriptase inhibitors-based antiretroviral therapy Chin Med J 123: 3587-3590.

38. Mullen JT, Kobayashi W, Wang JJ, Harmon DC, Choy E, et al. (2011) Long term follow-up of patients treated with neoadjuvant chemotherapy and radiotherapy for large, extremity soft tissue sarcomas. Cancer.

39. Berlanga-Acosta J, Gavilondo-Cowley J, del Barco-Herrera DG, Martín- Machado J, Guillen-Nieto G (2011) Epidermal Growth Factor (EGF) and PlateletDerived Growth Factor (PDGF) as Tissue Healing Agents: Clarifying Concerns about their Possible Role in Malignant Transformation and Tumor Progression. J Carcinogene Mutagene 1: 115.

40. Pereira RFC, Alves DA, Jacinto RK, Hollanda LMde, Verinaud LMC, et al. (2011) Effects of Neisseria meningitidis Infection in Tumor Glioblastoma Cell Line NG97: Respiratory Pathogen Inducing Apoptosis. J Bacteriol Parasitol 2 114

41. Shirode AB, Sylvester PW (2011) Mechanisms Mediating the Synergistic Anticancer Effects of Combined $y$-Tocotrienol and Celecoxib Treatment. J Bioanal Biomed 3: 1-7.

42. Cañas-Alonso RC, Fuentes-Noriega I, Ruiz-Azuara L (2010) Pharmacokinetics of Casiopeína Ilgly in Beagle Dog: A Copper Based Compound with Antineoplastic Activity. J Bioanal Biomed 2: 028-034.

43. Costa JV, Garbi Novaes MRC, Asquieri ER (2011) Chemical and Antioxidant Potential of Agaricus sylvaticus Mushroom Grown in Brazil. J Bioanal Biomed 3: 049-054.

44. Sudhakar A (2009) History of Cancer, Ancient and Modern Treatment Methods. J Cancer Sci Ther 1:1-5.

45. Sadeghifard N, Ghafourian S, bin Sekawi Z, Neela VK, Hematian A, et al (2011) Extended Spectrum Beta-Lactamases Among Hospitalized Patients in Surgery Wards, Ilam, Iran. J Microbial Biochem Technol 3: 18-20.

46. Gao H, Zhang Y, Tan Y, Wang L, Xiao X et al. (2011) Transcriptional regulation of ompF2, an ompF paralogue, in Yersinia pestis. Can J Microbiol 57: 468-475.

47. Paganelli FL, Willems RJ, Leavis $\mathrm{HL}$ (2011) Optimizing future treatment of enterococcal infections: attacking the biofilm? Trends Microbiol 20: 40-49.

48. Okandeji BO, Greenwald DM, Wroten J, Sello JK (2011) Synthesis and evaluation of inhibitors of bacterial drug efflux pumps of the major facilitator superfamily Bioorg Med Chem 19: 7679-7689. 
Citation: Praveenya P, Singh BK, Sathish Kumar D, Kalyan P (2012) Antibiotic Resistance Creating New Epoch. J Bacteriol Parasitol 3:131 doi:10.4172/2155-9597.1000131

49. Bouffartigues E, Gicquel G, Bazire A, Fito-Boncompte L, Taupin L, et al. (2011) The Major Outer Membrane Protein Oprf is Required for Rhamnolipid Production in Pseudomonas aeruginosa. J Bacteriol Parasitol 2: 118.

50. Chang EL, Olinger GG, Hensley LE, Lear CM, Scully CE, et al. (2011) Hexamminecobalt (III) Chloride As a Broad-Spectrum Antiviral Complex. J Antivir Antiretrovir 3: 20-27.

51. Wadi M, Al Fadhil, Khalid S (2011) Treatment of Cutaneous Leishmaniasis by Topical Application of Honey. J Bacteriol Parasitol 2: 110.

52. El-Gendy MMA (2010) In vitro, Evaluation of Medicinal Activity of Egyptian Honey from Different Floral Sources as Anticancer and Antimycotic Infective Agents. J Microbial Biochem Technol 2: 118-123.

53. Ghashm AA, Othman NH, Khattak MN, Ismail NM, Saini R (2010) Antiproliferative effect of Tualang honey on oral squamous cell carcinoma and osteosarcoma cell lines. BMC Complement altern Med 10: 49

54. Shasha SM, Sharon N, Inbar M (2004) Bacteriophages as antibacterial agent. Harefuah 143: 121-125.

55. Du Y, Yoo D, Paradis MA, Scherba G (2011) Antiviral Activity of Tilmicosin for Type 1 and Type 2 Porcine Reproductive And Respiratory Syndrome Virus In Cultured Porcine Alveolar Macrophages. J Antivir Antiretrovir 3: 28-33.

56. Capparelli R, Parlato M, Borriello G, Salvatore P, lannelli D (2007) Experimental phage therapy against Staphylococcus aureus in mice. Antimicrob Agents Chemother 51: 2765-2773.

57. Ryan EM, Gorman SP, Donnelly RF, Gilmore BF (2011) Recent advances in bacteriophage therapy: how delivery routes, formulation, concentration and timing influence the success of phage therapy. J Pharm Pharmacol 63: 12531264.

58. Gupta SM, Gupta AK, Ahmed Z, Kumar A (2011) Antibacterial and Antifungal Activity in Leaf, Seed Extract and Seed Oil of Seabuckthorn (Hippophae salicifolia D. Don) Plant. J Plant Pathol Microbiol 2: 105.

59. Wang N,WangY, Li P, Peng W, Xie T, et al. (2009) The Bioavaliability of Hepatoprotective Flavoniods in Hypericum Japonicum Extract. J Bioanal Biomed 1: 33-38.

60. Lu C, Xin Y, Xu Y, Zhao Z, Fu J, et al. (2011) Luteolin sensitizes Fas/ FasL-induced apoptosis in HepG2 cells through inhibiting Akt Activation and promoting XIAP Degradation. J Carcinogene Mutagene 2: 121.

61. Khan MS, Ahmad I (2011) Antibiofilm activity of certain phytocompounds and their synergy with fluconazole against Candida albicans biofilms. J Antimicrob Chemother [Epub ahead of print].

62. González-Sarrías A, Li L, Seeram NP (2011) Effects of Maple (Acer) Plant Part Extracts on Proliferation, Apoptosis and Cell Cycle Arrest of Human Tumorigenic and Non-tumorigenic Colon Cells. Phytother Res [Epub ahead of print].

63. Shirotake S, Nakamura J, Kaneko A, Anabuki E, Shimizu N (2009) Screening Bactericidal Action of Cytoplasm Extract from Kumazasa Bamboo (Sasa veitchii) Leaf against Antibiotics-Resistant Pathogens such as MRSA and VRE Strains. J Bioequiv Availab 1: 80-85.

64. Riju A, Sithara K, Nair SS, Shamina A, Eapen SJ (2009) In Silico Screening Major Spice Phytochemicals for their Novel Biological Activity and Pharmacological Fitness. J Bioequiv Availab 1: 63-73.

65. Prakash N, Devangi P (2010) Drug Discovery. J Antivir Antiretrovir 2: 63-68. 